\title{
Passive design strategies and performance of Net Energy Plus Houses
}

\author{
Edwin Rodriguez-Ubinas . ,Claudio Montero , María Porteros , Sergio Vega , \\ Iñaki Navarro ， Manuel Castillo-Cagigal , Eduardo Matallanas , Alvaro Gutiérrez
}

\begin{abstract}
A B S T R A C T
The first step in order to comply with the European Union goals of Near to Zero Energy Buildings is to reduce the energy consumption in buildings. Most of the building consumption is related to the use of active systems to maintain the interior comfort. Passive design strategies contribute to improve the interior comfort conditions, increasing the energy efficiency in buildings and reducing their energy consumption. In this work, an analysis of the passive strategies used in Net Energy Plus Houses has been made. The participating houses of the Solar Decathlon Europe 2012 competition were used as case studies. The passive design strategies of these houses were compared with the annual simulations, and the competition monitored data, especially during the Passive Monitored Period. The analysis included the thermal properties of the building envelope, geometric parameters, ratios and others passive solutions such as Thermal Energy Storage systems, evaporative cooling, night ventilation, solar gains and night sky radiation cooling. The results reflect the impact of passive design strategies on the houses' comfort and efficiency, as well as their influence in helping to achieve the Zero Energy Buildings category.
\end{abstract}

\section{Introduction}

The Energy Performance of Buildings Directive (EPBD) [1], published in 2002, constitutes a significant step of the European Union to maintain competitiveness, security of energy supply and meet the commitments on climate change made under the Kyoto protocol. This directive emphasizes two main aspects: the reduction of the energy consumption and the improvement of the energy efficiency in buildings. The recast EPBD was adopted eight years later [2], introduce new requirements related to the Zero Energy Building (ZEB), for both existing and new construction. This directive settles the necessity to develop Near to Zero Energy Buildings (Near to ZEB). Buildings must increase their energy efficiency and generate energy to compensate their consumption. In this directive, Near to ZEB is defined as a building that has very high energy performance, and the nearly zero or very low amount of energy required is covered to a very significant extent by energy from renewable sources, produced on-site or nearby. This is a definition with several undefined terms, accompanied by phrases as nearly, very high, very low and very significant. It is not determinate how near to zero is enough to be considered Near to ZEB. Additionally, there are other imprecise items in the directive as the balance period, the balance boundary, the balancing method and energy weighting factors. Several researchers are working on clarifying and harmonizing the existing definitions, and proposing energy balance methods [3-6].

Despite the indefiniteness in the recast $E P B D$, this directive emphasizes fundamental aspects of the ZEB. One of them is that these buildings must have high energy performance. The first EPBD indicates that, to achieve high energy performance, it is necessary to reduce consumption and increase the efficiency of buildings' systems and services. Most of the energy consumption in buildings is related to protection from the external climate, and the need to use mechanical systems to maintain a comfortable indoor environment [7]. Therefore, the passive design strategies are a significant key to achieve the goals of the both EPBD. Passive strategies may help to increase the interior comfort, reducing the need of active HVAC systems.

Solar Decathlon Europe (SDE) is a biennial international competition based on the American Solar Decathlon competition organized by the U.S. Department of Energy (DOE). The SDE was created through an agreement signed between the governments of Spain and United States. These competitions challenge university students from all over the world to design, build and operate 
sustainable Zero Energy houses [8]. Since the SDE houses are grid connected, upon verifying that they comply with the ZEB requirement, they can be termed Net ZEB. In relation with Net ZEB, Voss et al. $[9,10]$ remark that this term is commonly used to describe the synergy between energy efficiency buildings and the renewable energy utilization to get an energy balance over an annual cycle.

During the final phase of the SDE competition, each participating team assembles its house in Madrid at the competition site, named as 'Villa Solar'. There, the houses performance is continuously monitored while undergoing the ten consisting contests of the competition. There are two types of contests: juried contest, evaluated by a multidisciplinary jury, and measured contests, evaluated by means of measurements in real time [11].

SDE rules promote the implementation of passive strategies as a way to reduce building energy consumption and increase their efficiency [12,13]. From the preliminary house design, the participating teams must describe the passive solutions that they plan to use. The teams must carry out energy simulation on their houses in each phase of the project. With these simulations, they can verify the effectiveness of theirs design strategies. The houses passive behavior plays a decisive role in the competition since to succeed they must operate with low energy consumption. The use of passive solutions contributes to earn points in both monitored and juried contests. Proper selection of passive strategies has a direct influence on the results of two monitored contests: comfort conditions and energy balance. While the houses were in the 'Villa Solar', the effectiveness of theirs passive design solutions, at least for weather conditions on those days, was evaluated by the SDE monitoring system [14]. Additionally, passive design strategies are taking into account by most of the juries: architecture, engineering, energy efficiency, sustainability and market viability.

The comfort conditions contest includes several sub-contests. The present analysis only included those that require energy consumption: interior temperatures, relative humidity, air quality and lighting level. The comfort conditions scoring stopped during the public visits, and started, again, $1 \mathrm{~h}$ after finished these periods. For dry bulb temperature monitoring, there were two sensors in each house, installed in poles at $150 \mathrm{~cm}$ from the finishing floor level. One was placed at the center of the living room and the other in the bedroom. In the temperature sub-contest, Teams earned points when the interior temperature was between 20 and $28^{\circ} \mathrm{C}$, and it is necessary maintain the interior temperature between $23^{\circ} \mathrm{C}$ and $25^{\circ} \mathrm{C}$ to obtain all available points. Humidity sensors were located next to the temperature ones. Teams earned points maintaining the relative humidity between 25 and $60 \%$, and all available points were earned when the relative humidity level was between 40 and $55 \%$. An air quality sensor was located on the same pole as the temperature sensor, and all available points are earned by keeping the $\mathrm{CO}_{2}$ content in the air below $800 \mathrm{ppm}$. Also, a photometer was placed in the house workplace, and the light intensity of the area was measured following the competition schedule. Points were earned if the light level is maintained over $300 \mathrm{~lx}$.

In the SDE 2012 competition, even greater stress was laid on the use of passive design solutions. The rules included for the first time the Passive Monitored Period [13]. This period consisted of $56 \mathrm{~h}$, in which nothing in terms of monitoring or scoring changed, but the teams were able to use only passive systems or strategies to maintain the interior comfort. For the purposes of the competition, "passive" means any strategy or system that does not rely on thermodynamics cycles [15] or on devices designed to produce heat or cold.

The objective of the present work is to analyze the passive strategies as a help to achieve the goals of European Directives related with the ZEB, using the SDE 2012 houses were selected as case studies. The analysis is focused on how the passive design strategies may increase the interior comfort and contribute to the reduction energy consumption in buildings, and not include the study of the houses' energy production systems. It is organized as follows: Section 2 presents the passive strategies that help to achieve the Net Energy Plus Buildings. In Section 3, the Madrid city climate, building code requirements and appropriated strategies are explained. The analysis of the SDE 2012 houses' passive strategies is presented in Section 4 . Section 5 focuses on the thermal and energy performance of the participating houses. Finally, conclusions are expounded in Section 6.

\section{Passive strategies and the Net Energy Plus Houses}

Recast EPBD states that a very high energy performance building can be considered as a Near to ZEB if it meets the following two conditions: require a very low amount of energy and be able to cover a very significant amount of their energy requirements by renewable energy sources, produced on-site or nearby [2]. Very low energy buildings can be achieved through good design practices and the selection of energy efficiency building technologies [16]. The use of high efficiency HVAC, lighting, equipment and appliances, as well as an adequate control system, are effective ways to reduce the energy consumption. However, the potential energy saving through an optimized design process, minimizing the heating and cooling loads, is usually more influential than the use of innovative HVAC solutions [16].

The optimized low-energy building design starts with the understanding of the building use, its interior comfort necessities, as well as the study of the natural and environmental resources available on the building site. Then, passive strategies for comfort must be established, taking advantage of the natural resources available. The passive design includes strategies for hygrothermal comfort, daylighting and air quality conditions. In terms of hygrothermal comfort, the heating period strategies look to optimize direct and indirect solar gains, Thermal Energy Storage and the reduction of heat losses. On the other hand, cooling period strategies include: keeping the heat from building up, removing the built-up heat and reducing the heat-generating sources. Some authors propose, in addition, taking advantage of natural heat sinks [15]. Depending on climatic conditions, adding or reducing the humidity also can be an effective strategy to increase the interior comfort in cooling periods.

An explicative diagram of a "Very high energy performance building" is shown in Fig. 1. Very high energy performance buildings can be Energy Plus Building (PEB), Zero Energy Building (ZEB) or Near to Zero Energy Building (NZEB), depending on the balance between energy demanded and generated. The use of passive strategies is one of the key actions to achieve any ZEB categories since be a "very low energy consumption building" is the first requisite. In the present study analysis of passive strategies was done in five areas: building envelope, orientation and geometrical parameters, other passive solutions and hybrid solutions $[17,18]$.

\subsection{Building envelope}

Building envelope constitutes the limit between the interior and exterior conditions and its correct selection is one of the most effective ways to minimize the energy consumption related to interior thermal comfort. When the building envelope is conceived as a barrier that protect from the exterior conditions, the thermal transmittance ( $U$ value) is its most relevant characteristic. Building codes, as well as the voluntary certifications, are becoming more demanding in terms of the thermal transmittance of the envelope. In the literature, there has been some discussion as to whether the high standards of insulation may or may not lead to increased loads in summer. However, this can only be true if the average exterior 


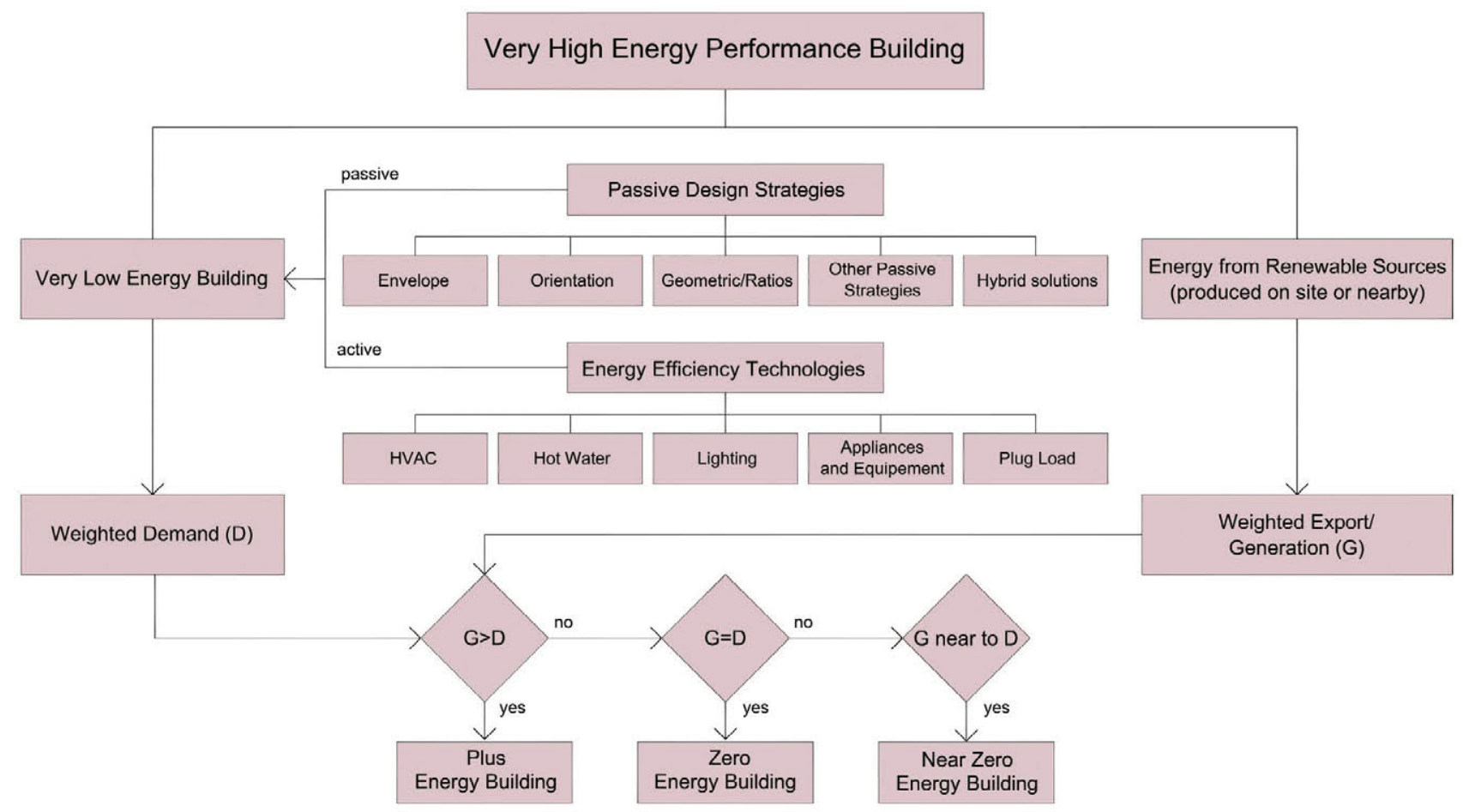

Fig. 1. Diagram of the ZEB approach. Passive design strategies an essential aspect to reduce the amount of energy required by the buildings.

temperature is lower than the indoor temperature in summer, an unusual situation even in the hotter climates of southern European countries [19]. Other parameters that affect the performance of the envelope are its absorptance, thermal lag and Thermal Energy Storage capacity. For translucent surfaces, in addition to their $U$ value, it is necessary to take into account their visible transmittance and solar heat gain. The importance of the building air tightness, like envelope $U$ value, increases with the severity of the climate.

\subsection{Building orientation, geometrical parameters and ratios}

Closely connected to the envelope' properties, there are other three factors that influence the thermal performance of buildings: orientation, geometric parameters and ratios. The thermophysical properties of the building envelope determine the gain or loss of thermal energy. Its shape determines the size of the exchange surface and the orientation determines what areas receive direct solar radiation and those that may be affected by the wind. Chiras [20]. Its orientation determines the potential use, or protection, of solar radiation and winds. The orientation can be analyzed in three levels: whole building, building's zones and glazed areas.

The ratios give an idea of proportion and relationship of the building elements. The aspect ratio $(w / l)$ is the relation between the equatorial-facing facade width $(w)$ and the lateral facade length ( $l$ ) [18]. This ratio in conjunction with the height and the roof type can determine the building shape [17]. However, buildings of the same shape and the same volume may have a different envelope area. Therefore, other ratios that relate the envelope area and the building volume should be used [17]. In this line, The European Committee for Standardization proposed two parameters to describe the shape of a building: compactness ratio and the shape factor [21]. The compactness ratio $\left(A_{\mathrm{e}} / V_{\mathrm{C}}\right)$ is the ratio of the thermal envelope area $\left(A_{e}\right)$ in $\mathrm{m}^{2}$ to the building volume $\left(V_{C}\right)$ in $\mathrm{m}^{3}$. The shape factor $\left(A_{\mathrm{E}} / A_{\mathrm{C}}\right)$ is the ratio between the thermal envelope area $\left(A_{\mathrm{e}}\right)$ and the building conditioned floor area $\left(A_{\mathrm{C}}\right)$, both in $\mathrm{m}^{2}$. These and other ratios that are used in the optimization process of the energy performance of the building are summarized in
Table 1. Additionally, there are other researchers that propose to use coefficients that relate some of the mentioned ratios [27-29].

The design of a high efficiency building is not a straightforward task; there are many elements that need to be solved and some of them conflict with others. In the literature, there are many studies that deal with the parametric optimization of the building design, analyzing one or more variables [17,22,24]. Evins [30], in his review of computational optimization methods for sustainable buildings, organized these studies into three: generic optimization, multi-objective optimization and algorithms. Brownlee et al. [31] focus their reviews on the existing approaches based on the analysis of multi-objective or multi-criteria optimization, using the Pareto approach. Recently, Attia et al. [32] raise the possibility of using automated mathematical building performance optimization paired with simulation of buildings performance.

\subsection{Other passive strategies and hybrid solutions}

There are other strategies that do not require external energy to improve the building performance. These passive strategies help to avoid undesirable climate conditions, taking advantage of the recourses offered by building location such as solar radiation, wind, thermal variability, daylight, clear skies and ground temperature. Fig. 2 shows these strategies grouped by their purpose: heating, cooling and Thermal Energy Storage (TES). This figure also shows a non-exhaustive list of hybrid or semi-passive solutions. These solutions use low energy devices for their functioning, such as small pumps or fans [33-35].

Each passive strategy is only valid for some climatic conditions. In the preliminary design stages, the application of a hygrothermal comfort model in a psychometric chart can help to identify adequate passive and hybrid solutions, also providing an approximate idea of their impact on the occupants' comfort, one of the computational tools that perform this preliminary psychometric analysis is Climate Consultant [37]. Nevertheless, to obtain a more precise idea about the improvement of the energy performance of the building it is necessary to carry out a dynamic energy building simulation. 
Table 1

Ratios used for building optimization.

\begin{tabular}{|c|c|c|c|}
\hline Name & Definition & Units & Reference \\
\hline Aspect ratio & $w / l$ & - & {$[17,18]$} \\
\hline Compactness ratio & $A_{\mathrm{e}} / V_{\mathrm{C}}$ & $\mathrm{m}^{2} / \mathrm{m}^{3}$ & {$[17,21-23]$} \\
\hline Shape factor & $A_{\mathrm{E}} / A_{\mathrm{C}}$ & - & [21] \\
\hline Envelope transparent surface ratio & $A_{\mathrm{t}} / A_{\mathrm{e}}$ & - & [24] \\
\hline Envelope transparent surface to floor area ratio & $A_{\mathrm{t}} / A_{\mathrm{c}}$ & - & {$[22-25]$} \\
\hline Envelope transparent surface to wall ratio & $A_{\mathrm{t}} / A_{\mathrm{w}}$ & - & {$[22-24]$} \\
\hline Envelope transparent surface to building volume & $A_{\mathrm{t}} / V_{\mathrm{C}}$ & $\mathrm{m}^{2} / \mathrm{m}^{3}$ & [23] \\
\hline South transparent surface to south wall ratio & $A_{\mathrm{st}} / A_{\mathrm{sw}}$ & - & {$[22,23,26]$} \\
\hline South transparent surface to floor area ratio & $A_{\mathrm{st}} / A_{\mathrm{c}}$ & - & {$[22,23]$} \\
\hline South transparent surface to building volume & $A_{\mathrm{st}} / V_{\mathrm{C}}$ & $\mathrm{m}^{2} / \mathrm{m}^{3}$ & \\
\hline South transparent surface to envelope transparent area & $A_{\mathrm{st}} / A_{\mathrm{t}}$ & - & \\
\hline
\end{tabular}

Indices: $w$ : width in $\mathrm{m} ; l$ : length in $\mathrm{m} ; A$ : area in $\mathrm{m}^{2}, V:$ volume in $\mathrm{m}^{3}$.

Subindices: e: envelope; $c$ : conditioned; t: transparent (glazing); w: wall; s: south.

\section{Madrid city}

\subsection{Climate}

Passive strategies are closely bound up with the climate where the building is located. The SDE 2012 houses were evaluated in Madrid. This city is $667 \mathrm{~m}$ above sea level with a Continental Mediterranean climate. Its climate is characterized by cold winters and hot summers, as well as dry air, clear skies, high diurnal thermal swings and high solar radiation. It has a global radiation of $4.88 \mathrm{kWh} / \mathrm{m}^{2}$ day [38].

\subsection{Code requirements for the buildings envelope in Madrid}

The Spanish Building Code (CTE) establishes twelve climate zones based on the climatic severities of winter (SCI) and summer (SCV). The code identifies five severities of winter represented by the letters from A (less severe) to $\mathrm{E}$ (most severe), and four climatic severities of summer represented by numbers from 1 (less severe) to 4 (most severe) [39]. The CTE identifies Madrid as D3, as a city with a high severity in both winter and summer.

The CTE is based on performance or objectives. It establishes basic requirements that buildings must meet. However, given the importance of the envelope, it includes some prescriptive elements related to optical and thermophysical characteristics of the building envelope. For the Madrid climate zone, the $U$ values in $\mathrm{W} / \mathrm{m}^{2} \mathrm{~K}$ must be lower than 0.66 for walls, 0.49 for floors and 0.38 for roofs. Similarly, there are minimum requirements of thermal transmittance of fenestration. These requirements depend on the orientation and the percentage of the glazing area. The transmittance of fenestrations oriented south varies from $3.5 \mathrm{~W} / \mathrm{m}^{2} \mathrm{~K}$, up to $30 \%$ of glazing to $3.0 \mathrm{~W} / \mathrm{m}^{2} \mathrm{~K}$ up to $60 \%$. The solar factor ( $g$-value) for south facing glazing, in buildings with low internal loads, is 0.61 and is only required when the percentage of glazing exceeds 50 [39].

\subsection{Passive solutions for Madrid city}

Madrid, as explained before, has cold and warm seasons; therefore, it is necessary to use appropriate strategies for these two contrasting climatic conditions. The high radiation points out the opportunity to take advantage of this in heating periods, and avoid their influence in the cooling ones. The high daily thermal swing enables the use of thermal mass to smooth the interior temperature and reduce the necessity of mechanical conditioning, in both heating and cooling periods. Evaporative cooling and night sky radiant cooling systems can be appropriate strategies due the Madrid dry air and clear skies.

A rough estimation on the potential impact of the use of passive or hybrid solutions on interior comfort was calculated with Climate Consultant 5.0 [37]. It was used the comfort model defined in the 2005 ASHRAE Handbook of Fundamentals [40]. This model is appropriate for the Madrid climate because it has two zones of comfort; one for the heavy clothing of the heating periods and another for the light clothing of the cooling ones. The Climate Consultant results are summarized in Table 2 . In this table, the strategies are ranked by the number of hours that can potentially be added to the comfort in each period, first analyzing each one individually and then combining solutions. These numbers of hours represent a rough estimate. The final result will depend on building design, and how the solutions are implemented. The values of this table help to determine the most appropriated solutions for the Madrid climate. During the heating periods, there is a significant potential to increase the comfort through internal loads. Additionally, a proper design of the building envelope and the use of thermal mass can help to reduce heat loss and extends the benefits the internal

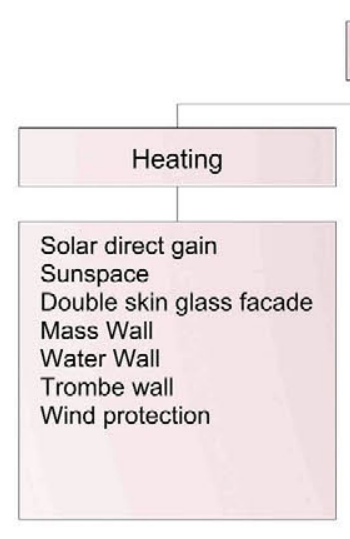

Other Passive Solutions

\begin{tabular}{|l|l|}
\hline \multicolumn{2}{|c|}{ Cooling } \\
\hline \multicolumn{2}{|c|}{$\mid$} \\
\hline Solar shading \\
Green roof \\
Natural ventilation \\
Night ventilation cooling \\
Ventilated facade or roof \\
Solar chimney \\
Evaporative cooling \\
Wind catcher \\
Green roofs or walls \\
\hline
\end{tabular}

\section{Hybrid Solutions}
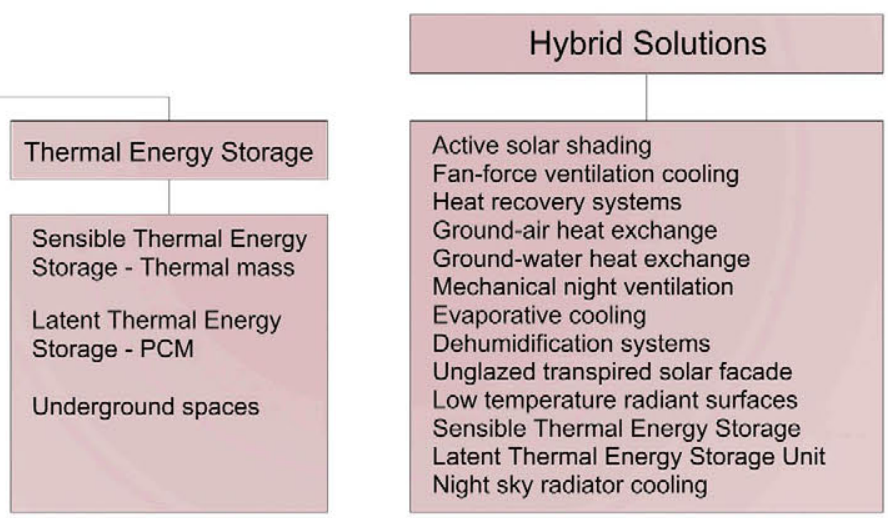

Fig. 2. Buildings' passive and hybrid solutions. 
Table 2

Potential amount of hours that could be added to the hygrothermal comfort due the use of passive solutions.

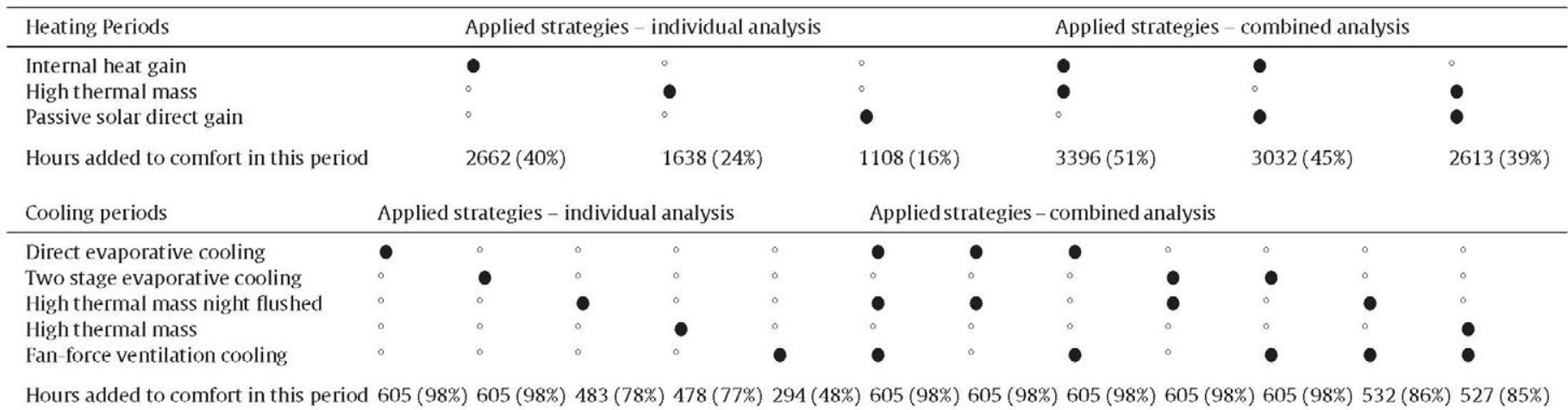

Psychometric analysis gives rough estimation of hours. The final amount of hours added to the comfort range depends on the building design and characteristics.

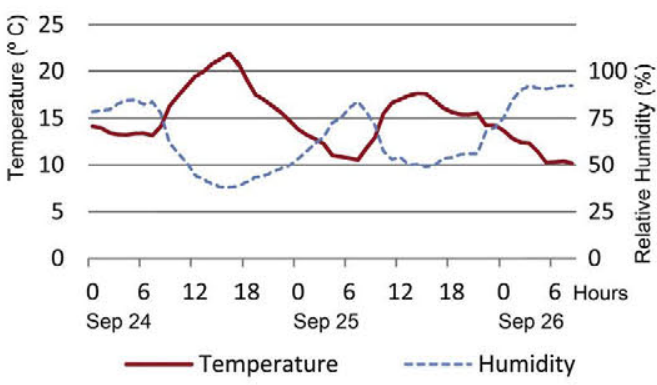

Fig. 3. Exterior temperature and relative humidity during the Passive Monitored Period.

load heat gains. In Madrid, in addition to traditional thermal mass, Latent Thermal Energy Storage (LTES) may be implemented. The use of Phase Change Materials in spaces with adequate orientation and glazing size, help to increase the number of hours within the thermal comfort range, reducing thermal peaks, smoothing the daily temperature swing [36].

On the other hand, for cooling periods, Fig. 3 shows that it necessary applies strategies that help to prevent overheating. The most basic passive strategy for these periods is the use of shading devices. Other appropriates strategies are included in Table 2, where can be sawn that in Madrid, during the cooling periods, adding humidity to the air is the most favorable strategy, followed by the use of thermal mass with night ventilation.

\subsection{Passive solutions appropriate for the Passive Monitored Period}

During the first six days of competition, the skies remained mostly clear, and temperatures fluctuated between 15 and $30^{\circ} \mathrm{C}$ following a similar pattern on each of these days. However, by the seventh day the weather changed. The Passive Monitored Period lasted from September 24th until the morning of the 26th. As Figs. 3 and 4 show, during the Passive Period there were cloudy skies, temperatures during midday barely exceeded $20^{\circ} \mathrm{C}$, and at nights temperatures fell to $10^{\circ} \mathrm{C}$. On September 25 th, there was a reduction of temperatures and direct solar radiation. In addition, humidity in the early hours of the 26th registered the highest values of the Passive Monitored Period.

During the Passive Monitored Period, the temperature and the humidity were measured continuously. As part of the evaluation of this period, $15 \mathrm{~min}$ average temperature values were calculated and plotted over a Madrid psychometric chart as shown in Fig. 5. This figure helps to identify the strategies that could be useful during this period. It was found that although these days correspond

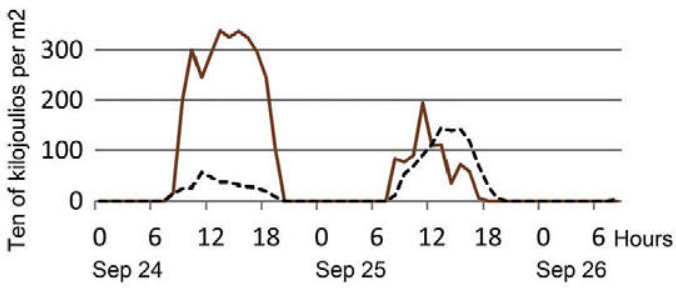

Sep $24 \quad$ Sep $25 \quad$ Sep 26

Fig. 4. Solar radiation during the Passive Monitored Period

to the summer season, most of the time, the temperatures remained below the comfort zone; so the strategies for heating periods were most appropriate. In these weather conditions, the adequate selection of the optical and thermophysical characteristics of the building envelope, the maximization of the solar gains and use Thermal Energy Storage systems are key strategies. Additionally, the airtight construction can useful since help to minimizes heat losses.

\section{SDE 2012 Net Energy Plus Houses: passive strategies}

The passive strategies used by the eighteen participating houses, named $\mathrm{H} 1$ to $\mathrm{H} 18$, were analyzed following the scheme described in Section 2: envelope, orientation, geometrical characteristics and ratios, and other passive and hybrid solutions. The houses' information was extracted from the project drawings, manuals and simulation input reports submitted by the participating teams to the SDE Organization.

\subsection{SDE 2012 houses: envelopes}

High insulation level, high performance glazing and airtightness constructions are commons to the SDE 2012 participating houses. As shown in Fig. 6, thermal transmittances of the houses' envelopes were lower than those required in the Spanish Building Code (CTE) for Madrid city [39]. The only one exception is the roof $U$-value of the H06, which was not lower than the $0.38 \mathrm{~W} / \mathrm{m}^{2} \mathrm{~K}$ required by the code, see Fig. $6 \mathrm{c}$. The maximum wall thermal transmittance permitted by code is $0.66 \mathrm{~W} / \mathrm{m}^{2} \mathrm{~K}$, and it was found that in thirteen houses (72\%) this value was lower than $0.20 \mathrm{~W} / \mathrm{m}^{2} \mathrm{~K}$. In four of these houses, the walls $U$-value were $0.10 \mathrm{~W} / \mathrm{m}^{2} \mathrm{~K}$. Similarly, the fenestrations used also far exceed the code requirements. It is required that the windows $U$-value must be lower than 3.5 , or than $3.0 \mathrm{~W} / \mathrm{m}^{2} \mathrm{~K}$, depending on the window-to-wall ratio. However, ten houses had windows $U$-value equal to or lower than $1.0 \mathrm{~W} / \mathrm{m}^{2} \mathrm{~K}$. The fifteen houses have windows $U$-values lower than $1.5 \mathrm{~W} / \mathrm{m}^{2} \mathrm{~K}$. 


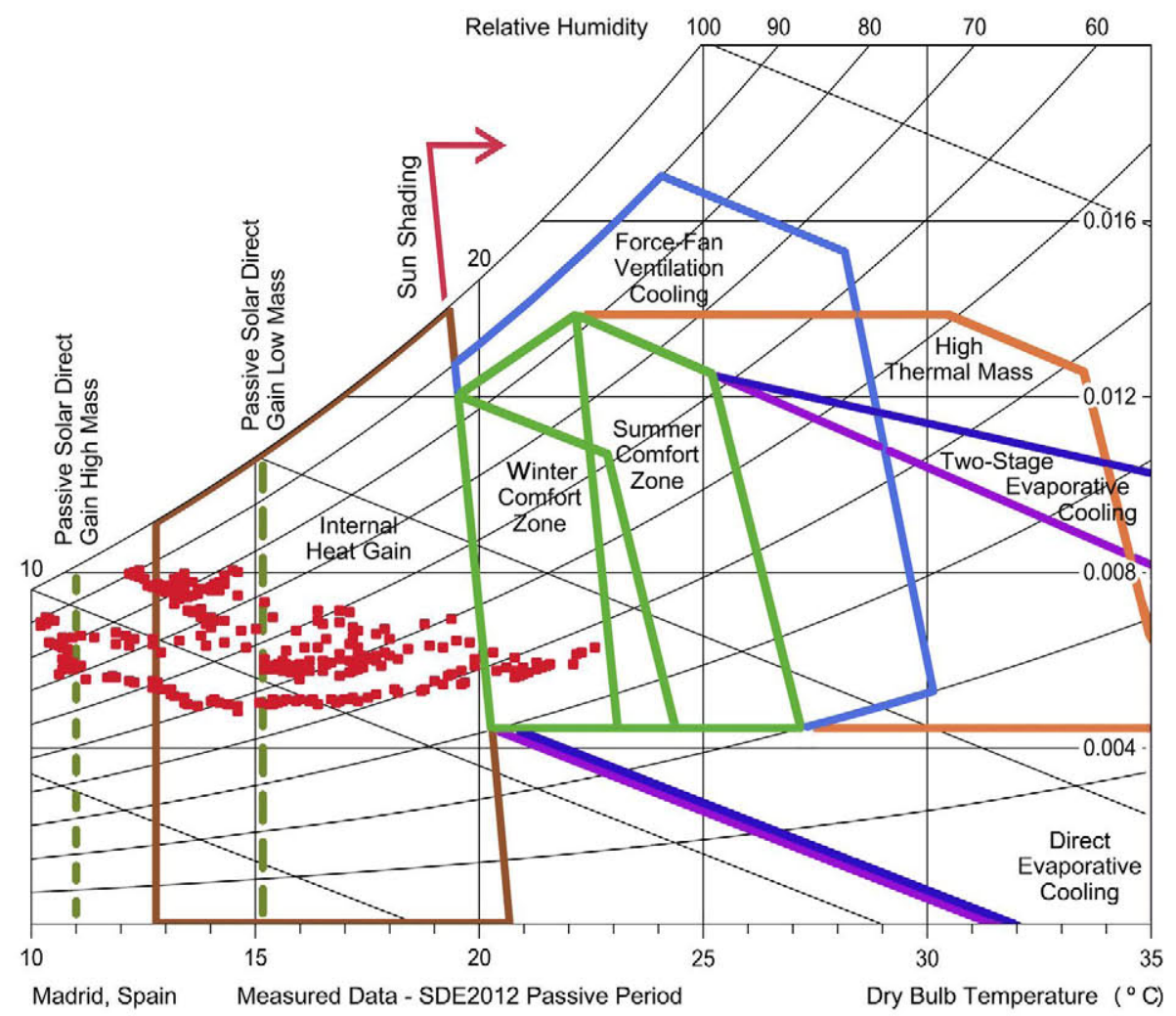

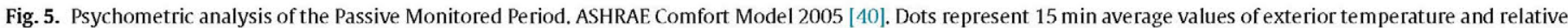
humidity.

\subsection{SDE 2012 houses: geometric characteristics and ratios}

For the analysis of the geometric parameters and ratios, the houses that obtained the highest scores in the interior temperature

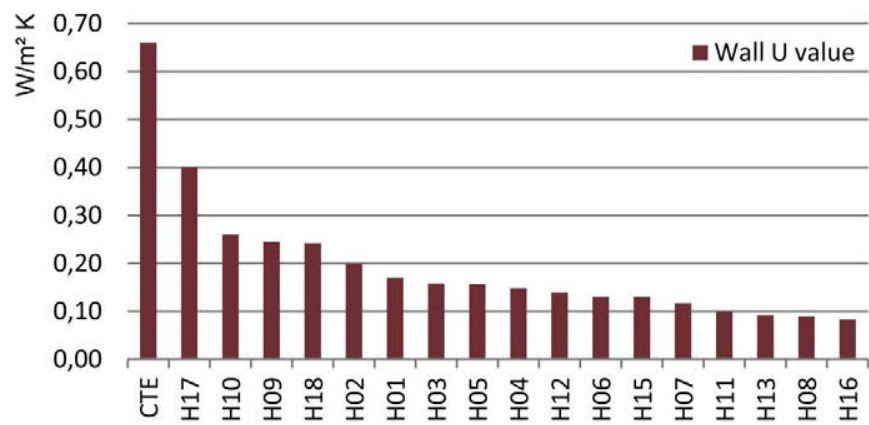

a. Walls thermal transmittance

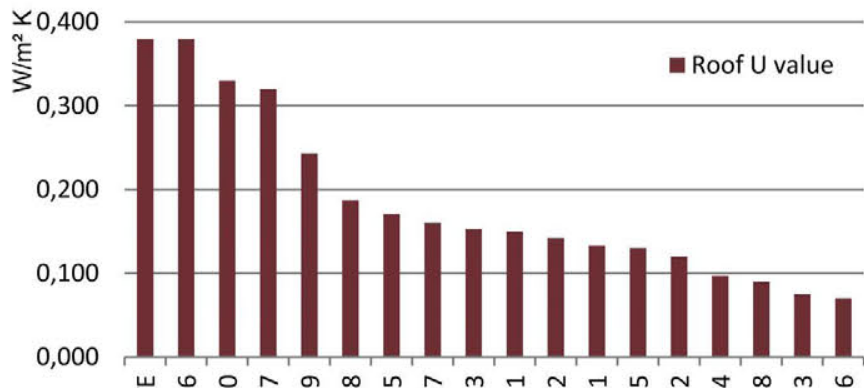

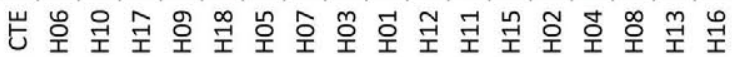

c. Roofs thermal transmittance sub-contest during the Passive Monitored Period were selected. As Table 3 shows, houses $\mathrm{H} 16, \mathrm{H} 01$ and $\mathrm{H} 13$ have both the lower aspect and compactness ratios. These houses had the lowest surface of thermal exchange per conditioned volume. Furthermore, house H7

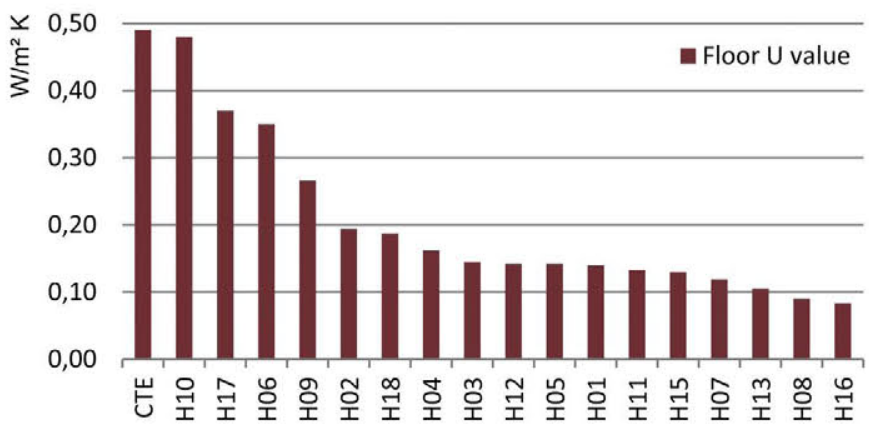

b. Floors thermal transmittance

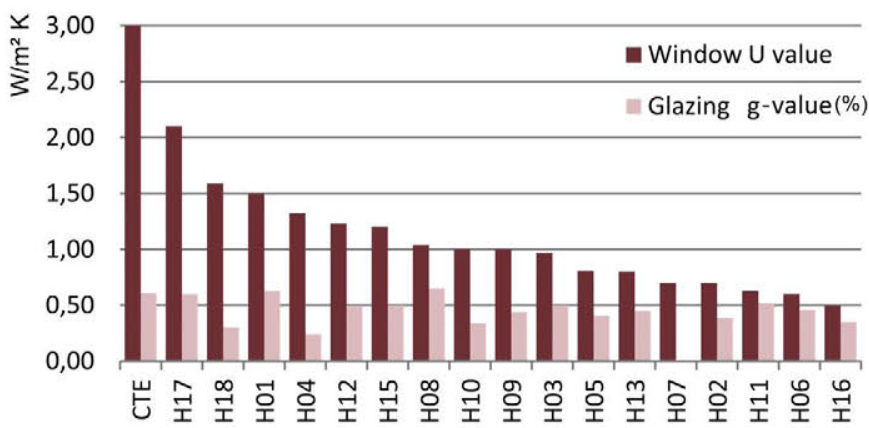

d. Windows thermal transmittance and Solar Factorns

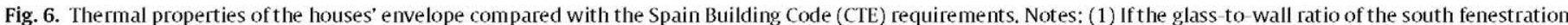

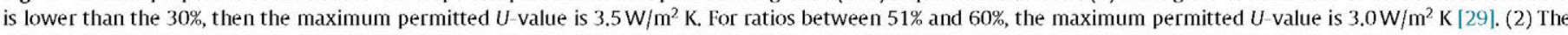
solar factor ( $g$-value) value is regulated only if the glass-to-wall ratio is between $51 \%$ and $60 \%$ [29]. In those cases, the maximum solar factor value is 0.6 . 
Table 3

Analysis ratios values of the houses that obtained the highest scores in the temperature sub-contest during the Passive Monitored Period.

\begin{tabular}{|c|c|c|c|c|c|c|c|c|c|}
\hline Ratio & Definition & H16 & H01 & $\mathrm{HO7}$ & $\mathrm{H} 11$ & H15 & $\mathrm{H} 12$ & $\mathrm{H} 13$ & Average \\
\hline Aspect ratio & $w / l$ & 1.00 & 1.05 & 1.58 & 1.48 & 2.23 & 1.62 & 0.87 & 1.40 \\
\hline Compactness ratio & $A_{\mathrm{e}} / V_{\mathrm{C}}$ & 0.93 & 0.85 & 1.63 & 1.34 & 1.19 & 1.32 & 0.80 & 1.15 \\
\hline Building shape factor & $A_{\mathrm{E}} / A_{\mathrm{C}}$ & 3.06 & 2.92 & 4.18 & 3.04 & 3.09 & 3.44 & 4.27 & 3.43 \\
\hline Envelope transparent surface ratio & $A_{\mathrm{t}} / A_{\mathrm{e}}$ & 0.13 & 0.16 & 0.30 & 0.27 & 0.11 & 0.22 & 0.25 & 0.20 \\
\hline Envelope transparent to floor ratio & $A_{\mathrm{t}} / A_{\mathrm{c}}$ & 0.36 & 0.43 & 1.07 & 0.96 & 0.31 & 0.74 & 0.68 & 0.65 \\
\hline Envelope transparent to wall ratio & $A_{\mathrm{t}} / A_{\mathrm{w}}$ & 0.27 & 0.33 & 0.71 & 0.63 & 0.20 & 0.44 & 0.62 & 0.46 \\
\hline Envelope transparent to building volume & $A_{\mathrm{t}} / V_{\mathrm{C}}$ & 0.12 & 0.13 & 0.49 & 0.37 & 0.13 & 0.28 & 0.20 & 0.25 \\
\hline South glazing to south wall ratio & $A_{\mathrm{st}} / A_{\mathrm{sw}}$ & 0.60 & 0.68 & 0.59 & 0.85 & 0.11 & 0.58 & 0.29 & 0.53 \\
\hline South glazing to floor ratio & $A_{\mathrm{st}} / A_{\mathrm{c}}$ & 0.19 & 0.25 & 0.28 & 0.32 & 0.07 & 0.40 & 0.25 & 0.25 \\
\hline South glazing to building volume & $A_{\mathrm{st}} / V_{\mathrm{C}}$ & 0.07 & 0.08 & 0.13 & 0.12 & 0.03 & 0.16 & 0.07 & 0.09 \\
\hline South glazing to envelope transparent area & $A_{\mathrm{st}} / A_{\mathrm{t}}$ & 0.53 & 0.58 & 0.26 & 0.33 & 0.23 & 0.55 & 0.36 & 0.41 \\
\hline
\end{tabular}

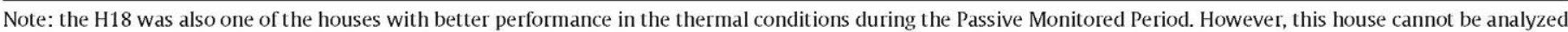
in the same way of other houses, due its singular configuration. Its living spaces are separated units locate inside an external greenhouse structure.

had the highest values of the transparent surfaces ratios. The south is the most beneficial orientation for glazing in the northern hemisphere, in terms of solar gains. Houses $\mathrm{H} 11$ and H01 had the highest South Glazing to South Wall ratios. Additionally, all these houses have $41 \%$ of their glazed surface at the south facade.

\subsection{SDE 2012 houses: other passive strategies and hybrid solutions}

Passive strategies and hybrid solutions used in the SDE 2012 houses are summarized in Table 4. Fig. 7, in turn, shows the percentages of the houses which applied some of these strategies. Table 4 shows that use of a high performance envelope was a key passive design element of the houses. As explained in Section 4.1, they all have a thermal transmittance lower than the code requirements, but also $83 \%$ of them had an exterior insulation layer (Fig. 7a), an effective way to minimize thermal bridges, and as shown in Fig. 7b, $39 \%$ of the houses had ventilated facades (Fig. 7b). Additionally, these houses included other passive strategies and hybrid solutions. These solutions are classified in Table 4 as passive heating, passive cooling, interior space planning, the exterior design, Thermal Energy Storage systems and hybrid solutions.

In terms of interior space planning, thirteen houses located the living spaces in the south, taking advance of direct solar gain and daylight. In the planning phase, the inclusion of a foyer to reduce the losses due infiltration and the use of services spaces as thermal buffer zone are two effective strategies to increase the thermal performance of the houses. However, only three houses had foyers and only six teams confirmed in their documentation the use of thermal buffers zones.

For the cooling periods, the participant houses implemented various strategies including evaporative cooling, night sky radiant cooling, and night ventilation with Thermal Energy Storage System (TES). It was found that $67 \%$ of the houses used an evaporative cooling system as pointed out in Section 3.3 this is a key strategy for Madrid cooling periods, $7 \%$ of the houses including a night sky radiant cooling system and $87 \%$ of the houses used one or more TES systems. TES system may be designed also for heating periods. Some houses had Sensible TES systems based on heavy materials as concrete, stone or sand while others used Latent TES systems taking advance of the thermal storage capacity of Phase Change Materials (PCM). From the first editions of Solar Decathlon many houses had used Latent TES systems [41]. In the 2012, 61\% of the houses used the PCM passive or active applications.

The low temperature radiant surfaces provide an efficient way to heating or cooling the buildings, and even more if they have natural thermal energy sources as the SDE2012 houses. Radiant roof or floor, and in some cases both, were used in 50\% of the SDE 2012 houses.

\subsection{Other passive and hybrid solutions not used in the SDE 2012 houses}

As can be seen in Table 4, SDE 2012 houses use a wide variety of passive strategies and hybrid solutions. Most of these strategies and solutions are linked with the recommendations for Madrid city included in Section 3.3. However, there are other solutions, which have not been used in the 2012 houses, which were used in the 2010 edition [42].

In relation with the houses' envelope, SDE 2012 houses use a broad variety of insulation materials, some of them with low manufacturing process as sheep wool insulation, coming from recycling process as cellulose or most innovative as vacuum insulation panels and insulation mats based on aerogel combined with mineral wool. However, there were not Translucent Insulation Materials (TIM) as in the SDE 2010. In that edition, there was a house with a dynamic envelope with a translucent layer insulated with aerogel.

Related with the translucent or transparent envelope, the SDE2012 houses use high end solutions as multi paned Low-E glasses filled with inert gasses and vacuum glasses. However, there were not houses with electronically tintable dynamic glass, commonly named electrochomic glass, as in the 2010 edition.

Many SDE 2010 and 2012 houses use Latent Thermal Energy Storage (LTES) based in the use of Phase Change Materials (PCM). Nevertheless, neither in this edition nor the 2010, the houses have taken advance of the translucent possibilities of the PCM. At present, in the Solar Decathlon, there has been no translucent envelope with PCM.

Some of the passive conditioning system, presented in the 2010 , based in the traditional solutions for the dry and hot summer were not used in the 2012 houses. Some of them are wind towers with evaporative cooling and solar chimneys. Also in 2010, one of the houses used a Passive Downdraught Evaporative Cooling (PDEC), a hybrid low energy solution for cooling and ventilating buildings.

Some SDE 2010 houses integrated in their envelope, partitions of interior finishing solutions that reinterpret the use of earth and clay in the building construction. Some of the solutions were: earth prefab walls with pipes embedded for a radiant system, radiant clay panels with PCM, and pottery walls with "botijo effect" for interior evaporative cooling. These types of solutions were not used for the SDE 2012 houses.

\section{SDE 2012 Net Energy Plus Houses: performance}

The analysis SDE 2012 houses performance was done using the 'Villa Solar' short term monitoring and the houses' energy simulations. This analysis was carried out in two parts: one based on the behavior of the houses during the Passive Monitored Period and other on the houses energy performance. The energy performance of the houses was analyzed in terms of consumption and 
Table 4

Passive design strategies and hybrid solutions used by the SDE 2012 houses.

House

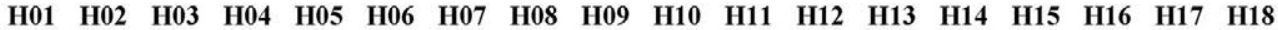

\section{Envelope}

Thermal transmittance lower than Code

Outside (or In/Out) insulation

Air tightness

Ventilated facade

High performance glazing

Multifunction facade

Envelope over spaces thermal envelopes

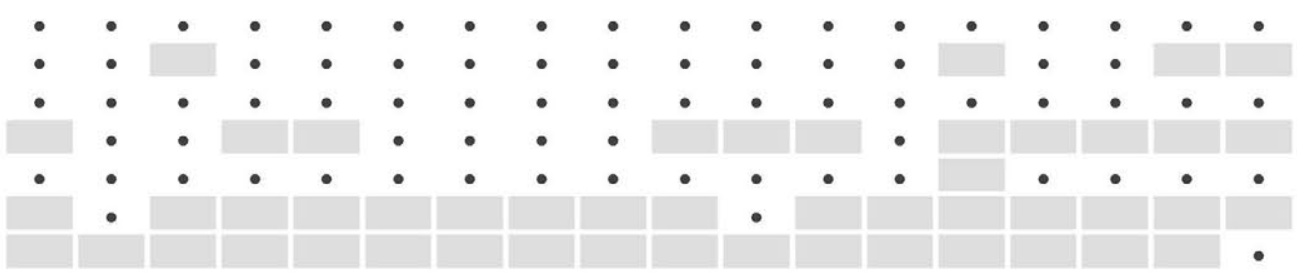

\section{Passive Heating}

Passive solar gain

Sunspace (glass balcony, glass terrace)

Double skin glass facade
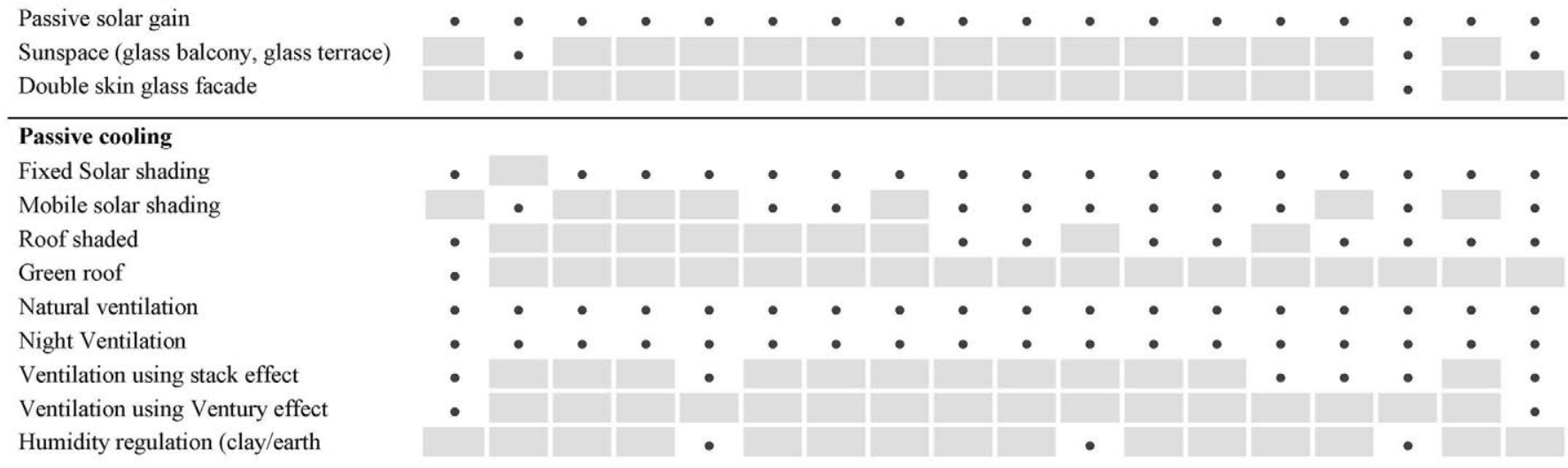

\section{Passive space planning and exteriors}

Foyer or entrance vestibule

Living areas south oriented

Interior buffer zone(s)

Patio

Attached covered spaces

Pond(s)/planted wetland

Vegetation

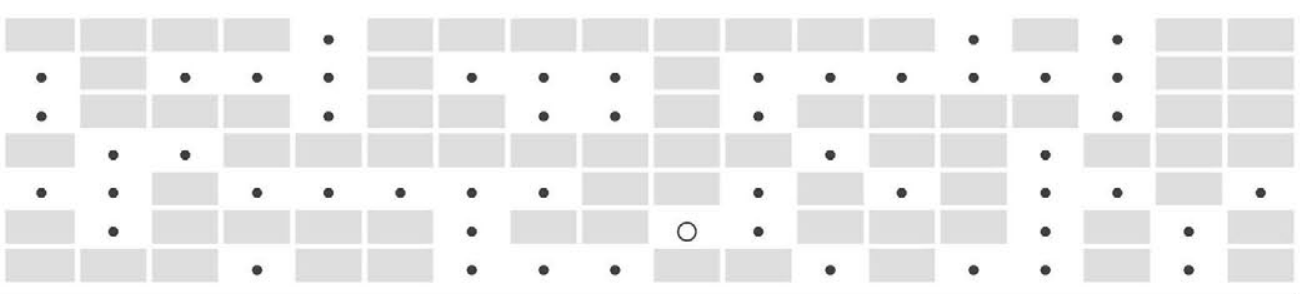

\footnotetext{
Hybrid systems

Mobile solar shading

Mechanical ventilation

Ventilation heat recovery

Mechanical (cooling) night ventilation

Ventilation (PCM heat exchange)

Evaporative cooling

Radiant floor

Radiant ceiling

Night sky radiation

Heating by ventilation using solar

Ground heat exchanger
}

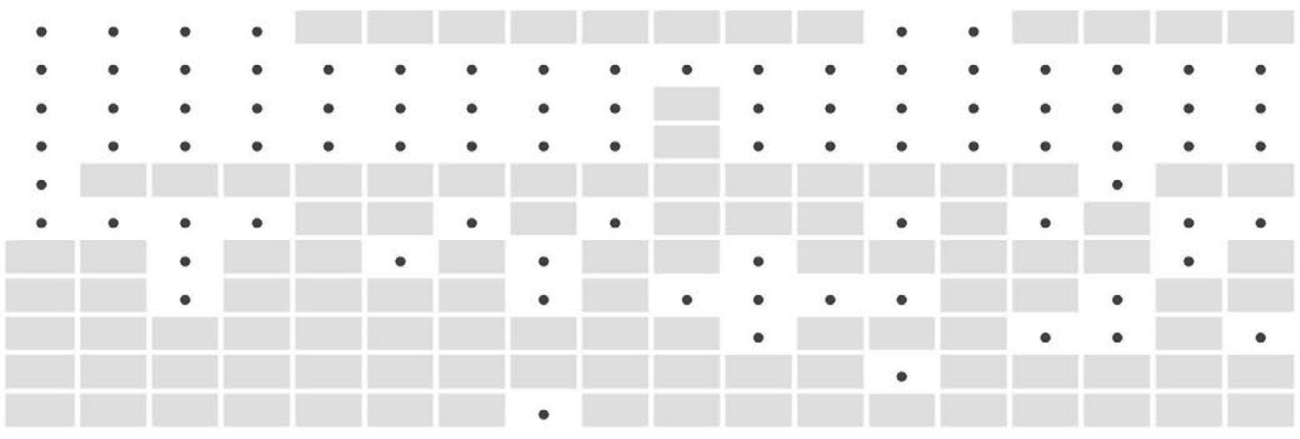

\footnotetext{
Thermal Energy Storage (TES) Sensible TES in floors

Sensible TES in walls and/or partitions Latent TES (PCM) in walls/partitions Latent TES (PCM) in floor Latent TES (PCM) in ceilings Latent TES (PCM) in furniture Sensible TES unit (liquids deposit/tank) Sensible TES unit (Solids deposit/bed) PCM Storage deposit (slurries) PCM Storage Unit(s)
}

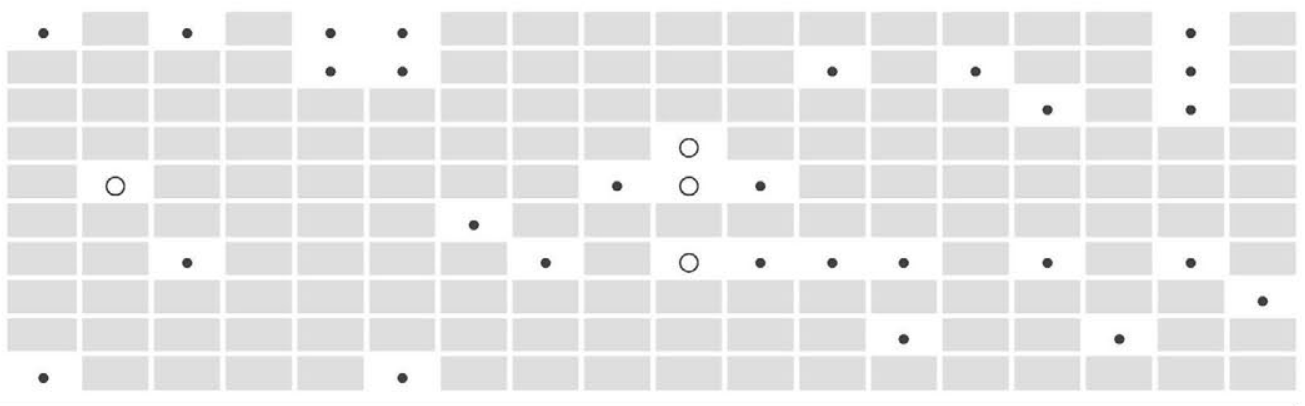

- Strategy of system used $\bigcirc$ strategy of system in the construction documents but not used in the Solar Village. 
14

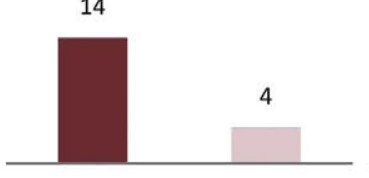

a. Outside (or In/Out) insulation

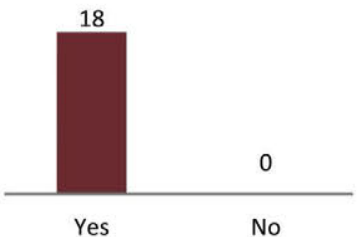

f. Thermal Energy Storage (See note below)

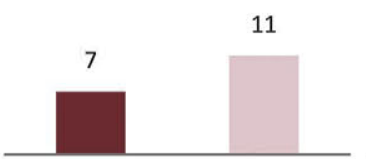

Yes

b. Ventilated facade

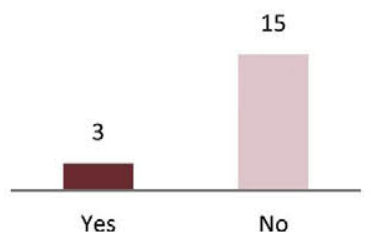

c. Foyer or entrance vestibule

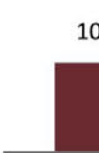

Yes

d. Evaporative Cooling

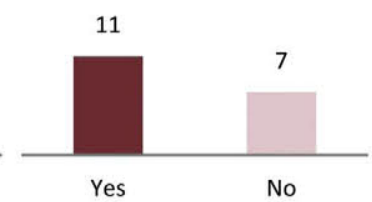

g. PCM - Latent TES

14

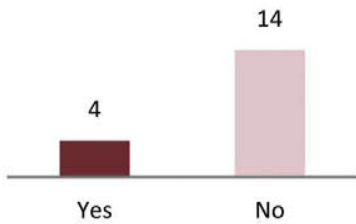

h. PCM storage unit

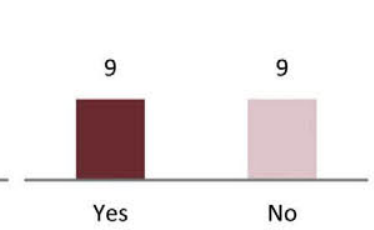

i. Radiance Floor or/and ceiling

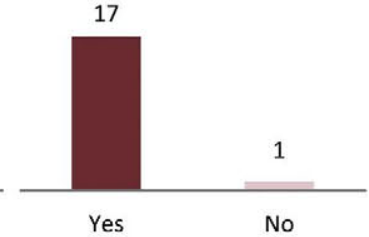

e. Ventilation with heat recovery

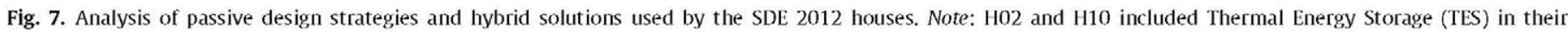
documentation, but they did not use the planned storage media in the Villa Solar.

production, taking into account both the performance in the 'Villa Solar' and the estimated values obtained from simulations.

\subsection{Passive Monitored Period: the houses' thermal performance}

Although the SDE houses use the passive strategies at all times, during most of the competition is not possible to analyze their passive performance since they may using at the same time active systems. As explained in the introduction, in the SDE 2012 was introduced the Passive Monitored Period. During $56 \mathrm{~h}$, the teams used only passive systems or strategies to maintain the interior comfort. For the purposes of the Competition, "passive" means any strategy or system that does not rely on thermodynamics cycles or on devices designed to produce heat or cold. Pumps and fans were allowed. However, electrical heaters, chillers, heat pumps or other equipment that include thermodynamics cycles were not allowed.

During the Passive Monitored Period, the thermal performance of most of the houses was remarkable. There were ten houses obtained more than $90 \%$ of the points available for the sub-contest of interior temperature as shown in Fig. 8. Only three houses obtained less than $80 \%$ of the score of thermal comfort during this period. Fig. 9 shows, the hourly interior temperatures of the five houses that obtained the highest scores during the Passive Monitored Period. These houses maintained the interior temperature all the time between 21 and $26^{\circ} \mathrm{C}$, using only passive strategies and hybrid systems. House $\mathrm{H} 16$ had the best score; it maintained the living room temperature between 23.1 and $25.4^{\circ} \mathrm{C}$ during all the passive period, and the bedroom temperature between 23.5 and $24.8^{\circ} \mathrm{C}$.

Although, as shown in Table 3, the houses used many passive strategies, only some of these strategies were useful to maintain the thermal comfort in the weather conditions experimented during the Monitored Period Passive. Seeking to determinate the influence of the envelope in the houses' performance, their $U$ values were compared with the houses thermal comfort results. Table 5 shows the information of the eight houses that get the highest scores on the thermal comfort sub-contest. Six of these eight houses also were among the eight houses with the lowest thermal transmittance of walls and floors. Similarly, five of them were among the eight lowest thermal transmittance ceilings. This finding, besides on the fact that these houses had a low heat losses during the nights (Fig. 9), it can be concluded that the envelope low $U$-value contributing significantly in the houses thermal comfort success. H16 had the envelope with the lowest thermal transmittance and got the highest score in this sub-contest as indicated in Table 4. House H18 was not between the eight houses with the lower envelope $U$ values, but its double envelope strategy, inspired in a greenhouse, help it to maintain the comfort during the Passive Monitored period, not matter the exterior temperature were mainly lower than the comfort temperatures.

In relation to maintain the heat gains, all the eight houses in Table 5 had Sensible or Latent Thermal Energy Storage systems. Four of these houses (H01, H11, H14, and H13) had both systems as shown in Table 4. Furthermore, it was also detected that the use of a foyer in the house H18 helps to maintain its interior thermal comfort and reduce the interior temperature fluctuations. On the

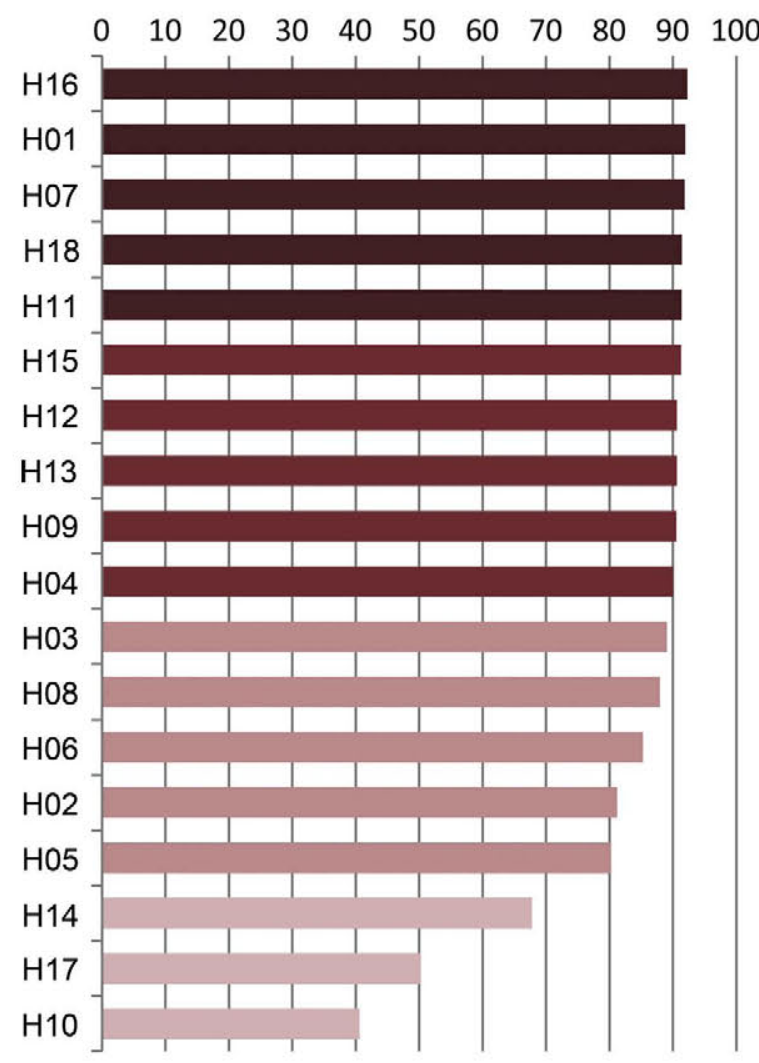

Fig. 8. SDE 2012 houses: thermal performance during the Passive Monitored Period. Bar represents the points earned in the interior temperature sub-contest. 

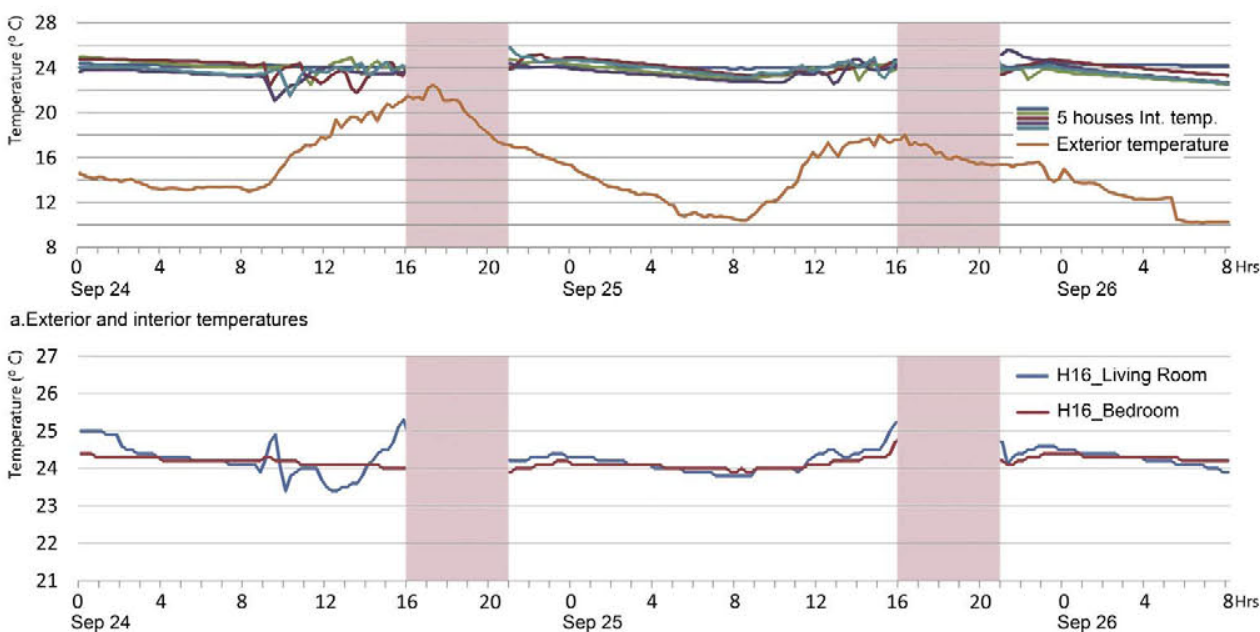

b. H16 interior temperature

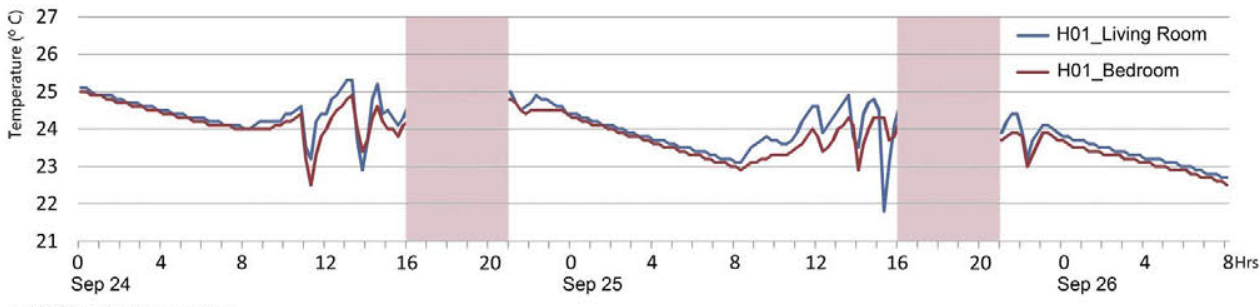

c. H01 interior temperature

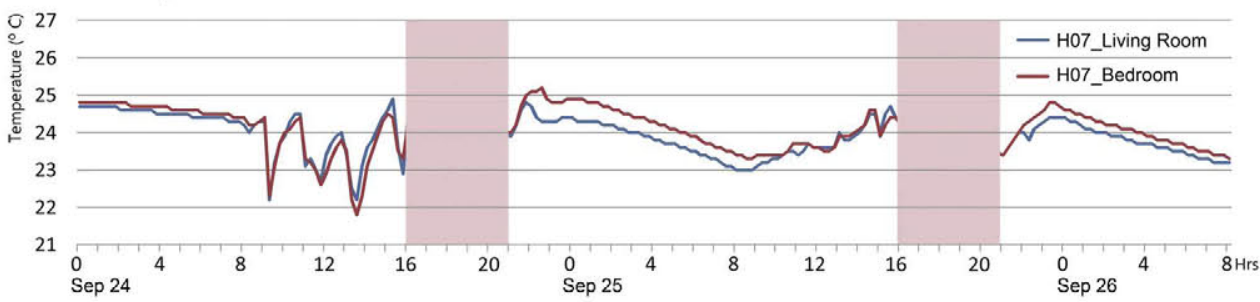

d. $\mathrm{H} 07$ interior temperature

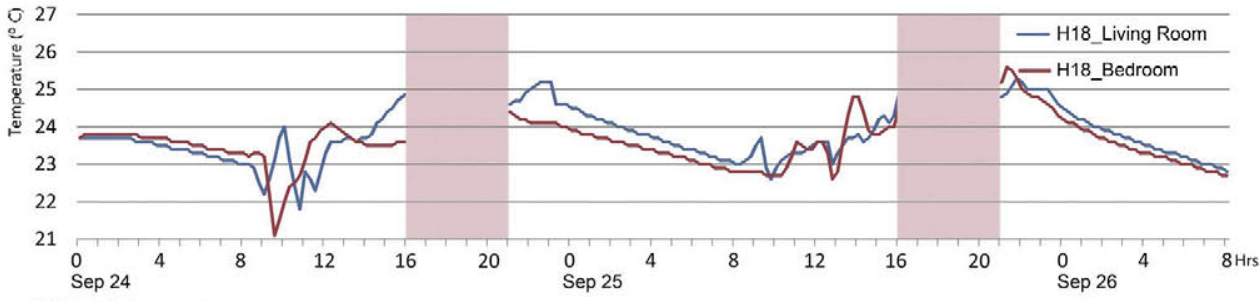

e. $\mathrm{H} 18$ interior temperature

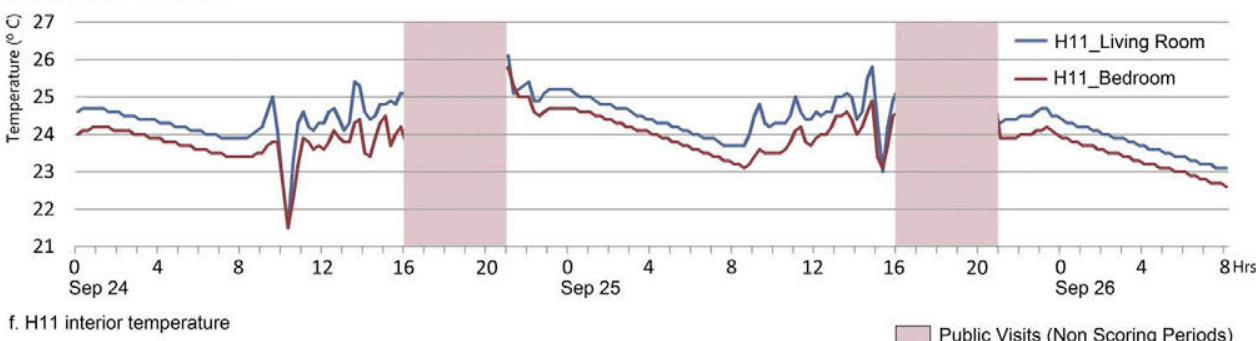

f. $\mathrm{H} 11$ interior temperature

$\square$ Public Visits (Non Scoring Periods)

Fig. 9. SDE 2012 houses: interior temperature during the Passive Monitored Period. Non scoring times due public visits are represented by the shaded areas.

contrary, houses without foyer registered temperature fluctuations due the doors opening as shown in Fig. 9.

\subsection{SDE 2012 houses: energy performance during the competition}

Passive design strategies have a significant influence on the energy performance of the houses. These strategies plus an appropriate selection of high efficiency HVAC equipment, controls and appliances were the basis of the low energy houses of the SDE 2012. To verify if SDE 2012 houses behaved as Energy Plus Buildings during the competition, the balance between energy production and consumption was analyzed. The SDE houses are all-electric buildings. This simplifies the energy balance equation since it is not needed weighting factors for the calculation; electricity is the only energy supplied and demanded. Comfort conditions and the Houses 
Table 5

Relation between the houses' thermal comfort during the Passive Monitored Period and the lowest envelope $U$ values,

\begin{tabular}{|c|c|c|c|c|c|}
\hline \multirow[t]{2}{*}{ House ID } & \multirow[t]{2}{*}{ Thermal comfort } & \multicolumn{4}{|c|}{ Thermal transmittance ranking (value in $\mathrm{W} / \mathrm{m}^{2} \mathrm{~K}$ ) } \\
\hline & & Walls & Floor & Roof & Windows \\
\hline H16 & $1 \mathrm{st}$ & 1st $(0.08)$ & 1st $(0.08)$ & 1st $(0.07)$ & 1st $(0.50)$ \\
\hline H01 & 2nd & - & $7 \operatorname{th}(0.14)$ & - & - \\
\hline $\mathrm{H} 07$ & 3rd & 5 th $(0.12)$ & $4 \operatorname{th}(0.12)$ & - & 5 th $(0.70)$ \\
\hline H18 & 4 th & - & - & - & - \\
\hline H11 & 5 th & $4 \operatorname{th}(0.10)$ & $6 \operatorname{th}(0.13)$ & $7 \operatorname{th}(0.13)$ & $3 \mathrm{rd}(0.63)$ \\
\hline H15 & 6 th & $6 \operatorname{th}(0.13)$ & $5 \operatorname{th}(0.13)$ & $6 \operatorname{th}(0.13)$ & - \\
\hline $\mathrm{H} 12$ & 7 th & 8 th $(0.14)$ & - & $8 \operatorname{th}(0.14)$ & - \\
\hline $\mathrm{H} 13$ & 8 th & $3 \mathrm{rd}(0.09)$ & $3 \mathrm{rd}(0.11)$ & 2nd (0.08) & 6 th $(0.80)$ \\
\hline
\end{tabular}

Note: Information provided by the participating teams.

Functioning contests in which energy is consumed. For that reason, for the energy performance analysis only the houses that obtained more than $70 \%$ of the points in these contests were included.

The results of continuous monitoring of the energy required and generated during the competition helped to study the energy performance of the houses during the competition. It is necessary take into account that SDE houses are all electric houses and consumption values in the analysis include all the loads: HVAC, DHW, lighting, equipment, appliances and other plug loads. The competition require an intensive use of hot water and appliances as well as maintain strict interior temperature and humidity ranges, this makes that consumption during the twelve days of the competition may was greater than typical day consumption. Even so, in all the fifteen houses the required energy was lower than their energy generation. All of them got a positive energy balance.

During competition's days the average consumption of the houses was $146 \mathrm{kWh}$ and the highest consumption was $198 \mathrm{kWh}$. As shown in Fig. 10, house H18 was the one with less energy consumption (107.25 kWh), this house also it was the house with the smallest PV installation (4.6 kWp) and was able to produce $159.15 \mathrm{kWh}$. Making an analysis of all the houses using the smallest PV array, it was found that during the completion days eleven of the fifteen houses (73\%) would have a positive energy balance and the other four houses would have a near to zero balance see Fig. 10.

\subsection{SDE 2012 houses: estimate anmual energy performance}

Passive Monitored Period is insufficient to determine the effectiveness of passive strategies on the annual performance of the houses. Similarly, twelve days of monitoring are not enough to determining the energy performance of the houses, no matter the weather variability presented during the SDE2012 competition. For the annual energy analysis, the energy simulation, carried out by the participating teams, was used. The results of these simulations provide an annual estimation of houses energy requirements and generation.

The average energy consumption of a detached house in Spain continental climate cities as Madrid is $19,774 \mathrm{kWh}$ [44]. The SDE 2012 houses are smaller than the average detached house in Madrid, but their estimated consumption is significantly lower. The average of SDE2012 houses estimated consumption is $5328 \mathrm{kWh}$, and the highest estimated consumption is $7587 \mathrm{kWh}$. In term of energy balance, in all the studied cases the estimated photovoltaic generation exceeds their demanded energy. Average estimated electrical energy generation of these houses is $13,396 \mathrm{kWh}$, being the highest estimated generation is $21,157 \mathrm{kWh}$.

As Fig. 11 shows, all the studied houses qualify to be classified as Energy Plus Buildings, if their final energy balance coincides with the estimated values. Indeed, being grid-connected houses, they could be classified as Net Energy Plus Buildings [9,10].

\section{Recommendations for upcoming SDE editions and future research}

\subsection{Recommendations for upcoming competitions}

During the development of the present research, it was found five circumstances, related with the SDE rules and monitoring system, which makes difficult carry out a more in-depth analysis of the passive performance of the houses or affect the functioning of some passive strategies. Some of these circumstances also have limited the findings of the present research.

$1 \mathrm{SDE}$, in addition of competition, is also an exhibition of sustainable houses. The fact to open the houses, for the public visits,

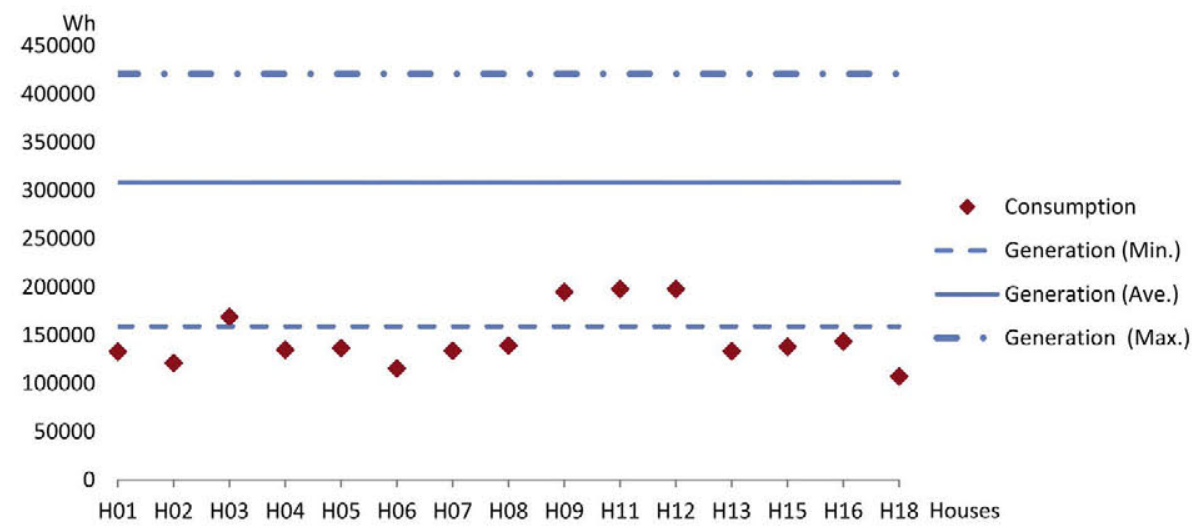

Fig. 10. SDE 2012 houses: energy consumption during the competition in relation with minimum, average and maximum energy generation. 


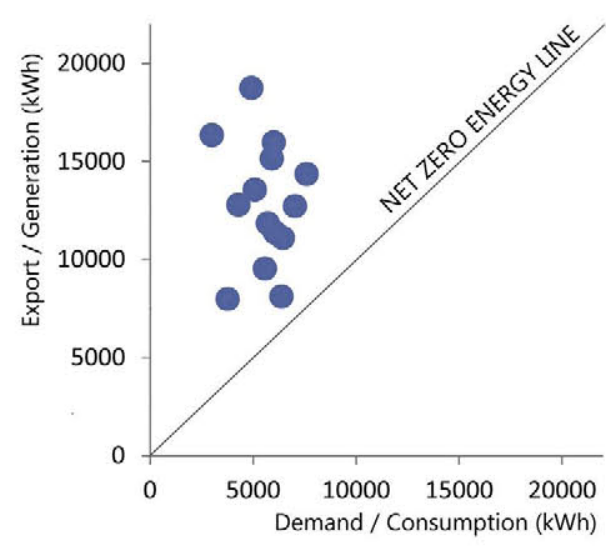

Fig. 11. SDE 2012 houses: annual estimated energy balance. Dots represent the annual estimated energy balance of the fifteen analyzed houses. Data provided by the participating teams. Graphic Model from University of Wuppertal, BTGA [6].

affects the house thermal performance. This is critical during the Passive Monitored Period. Many of the SDE houses based their thermal functioning in their thermal mass, high insulation and airtightness. Open the houses to the public exhibition shatter their strategies related with the Thermal Energy Storage in their houses' interior materials. The planned cycles of thermal energy charge and discharge are significantly affected. In relation to the research, the problems with the Thermal Energy Storage, and the discontinuity of the measurement do not permit obtain a complete understanding of the passive performance of the houses.

2 In relation with the thermal comfort, humidity and air temperature were measures continuously, but not the radiant temperature. The radiance temperature is a key parameter in the definition of the thermal sensation [43]. This parameter takes more relevance in the SDE since many of the house used thermal storage systems, and low temperature radiant systems, as can be seen in Table 4 . The monitoring of the radiant temperature will allow to evaluate the thermal comfort in term of operative temperature and to use the adaptive model.

3 In the SDE 2012, points related the thermal comfort are obtained maintaining the houses interior air temperature in a very narrow comfort range. This range was the same during the whole monitoring period. This reality penalized the teams that use night ventilation strategies as summer strategy, since the night fresh air has a lower temperature than the comfort range used in the competition. It is necessary to study the possibility to have a different conform range for the summer nights, taking into account that, during this period, the occupants can have a higher clo value.

4 Interior lighting levels is continuously measured in the house work station, however, adding other lighting sensors will bring a better idea about the houses daylight use. It is common in summer blocks the solar radiation to avoid the interior overheating, but some of the solar protection solutions significantly affect the daylight levels. It is necessary to promote the use solar protection solutions that permit the daylight use, getting and adequate balance between the thermal and lighting comfort, and reducing the daytime artificial light needs.

5 SDE 2012 monitoring system permits to know how much energy is used for the houses in real time. However, it does not permit to how much of this energy is used by houses' HVAC and DHW systems. For research purpose, it would be very helpful to add an independent electrical meter for monitoring the consumptions of these systems. That will allow to evaluate the efficiency of the active systems, but also, during the Passive Monitored Period, that will permit to know the consumption of the houses' hybrid systems.

\subsection{Future research}

Two week of monitoring and a passive period of only some days, it is not enough to get a complete understanding of the passive systems performance. Future researches shall be focused in the characterization of the passive and hybrid solutions used in the SDE 2012 in their final location. It is also needed to establish their economic feasibility and their payback period. For that, long term measurements are needed. These monitoring programs may include various types of experiment isolating some variables. The performance of the solutions must be evaluated in the different climatic conditions presented in the houses' location.

The ideal would be that all SDE houses might be monitored for at least one year in their final location. Create a monitoring network with the SDE houses. Develop a web platform in which the results be centralized. All the collected data and findings should be made available to researchers from all over the world.

\section{Conclusions}

There is a significant potential for the reduction of energy consumption in the building sector. Passive design strategies can help to reduce the energy consumption in buildings and achieve Energy Performance of Buildings Directive (EPBD) goals. The use of passive design strategies can help to reach the first requisite to achieve the Zero Energy Building category: be a very low energy building. In this paper, passive strategies and their influence in the buildings' performance were analyzed, using the following classification: building envelope, orientation, geometrical aspects, other passive strategies and hybrid solutions.

Solar Decathlon Europe (SDE) is an international competition of sustainable and high efficiency solar houses. The SDE has been successful in extending the understanding of the sustainable construction and the importance of passive design strategies to university students, professionals and the general public. Its rules emphasized the reduction of energy consumption in buildings, the increment of energy efficiency in buildings and the need to cover the energy demanded to a very significant extent with energy from renewable sources produced on-site. The addition of the Passive Monitored Period, in the SDE 2012, reinforces its interest to boost the use of passive design strategies. Given the close relationship between the objectives of the SDE and European Energy Performance of Buildings Directives, the participating houses of the Solar Decathlon Europe 2012 were selected as case studies. Since this year the 'Villa Solar' was set up in Madrid, an analysis of passive design strategies its climate was conducted as initial work. The research of the SDE2012 houses included the strategies used in this projects and their thermal behavior. Special attention was given to the houses thermal performance during the Passive Monitored Period. Additionally, the houses' energy performance and their energy balance were evaluated in two scenarios: during the competition and on an annual basis.

All participating houses included several passive design strategies. Many of them achieved an excellent balance between envelope, orientation, geometric aspects and other passive strategies. These strategies helped to maintain houses hygrothermal comfort and to reduce their energy consumption. During the Passive Monitored period, $56 \%$ of the SDE2 212 houses obtained more than $90 \%$ of the points available for interior temperature and $83 \%$ of them obtained more than $80 \%$ of the points. In relation to the Zero Energy Buildings, it was found that $100 \%$ of the houses analyzed in this section obtained a positive energy balance in both in the annual energy simulations and during their stay in the 'Villa Solar'. If their final energy balance is similar to the estimated one, all of them will qualify to be Net Energy Plus Buildings. 
It has been identified five recommendations for the upcoming Competitions. These suggestions may improve the assessment of passive strategies and theirs impact on the houses' thermal and energy performance. It is recommended: do not interrupt the Passive Monitored Period with public visits, measure the radiant temperature, study the possibility of used a different comfort temperature range at night, include additional lighting levels measurements and add a separate electric meters to monitoring HVAC systems energy consumption.

Finally, two week of monitoring and a passive period of only some days, it is not enough to get a comprehensive understanding of the passive systems performance. Future researches should be focused in the characterization of the passive and hybrid solutions used in the SDE 2012 houses in their final location, evaluating also their economic feasibility. These future researches should be based on long term monitoring programs.

\section{Acknowledgments}

The authors would like to thank the Spanish Meteorological Agency (Agencia Estatal de Meteorologia - AEMET) for their help and support. AEMET provided the weather data used in this research. E. Matallanas is sponsored by the Spanish Ministry of Education with a Ph.D grant (FPU-2011). M. Castillo-Cagigal is sponsored by the Spanish Ministry of Education with a Ph.D grant (FPU-2010). This work has been partly funded by the Spanish Science and Innovation Ministry under the IPT-2011-1468-920000 grant and the Economy and Competitiveness Ministry under the IPT-2012-1072-120000 grant.

\section{References}

[1] European Commission, Energy Performance of Buildings Directive 2002/91/EC (EPBD), European Parliament, 2002.

[2] European Commission, Energy Performance of Buildings Directive (recast) 2010/31/EU (EPBD), European Parliament, 2010

[3] A.]. Marszal, P. Heiselberg, J.S. Bourrelle, E. Musall, K. Voss, I. Sartori, A. Napolitano, Zero energy building - a review of definitions and calculation methodologies, Energy and Buildings 43 (4) (2011) 971-979.

[4] P. Torcellini, S. Pless, M. Deru, D. Crawley, Zero Energy Buildings: A Critical Look at the Definition, ACEEE Summer Stud, Pacific Grove, CA, USA, 2006.

[5] I. Sartori, A. Napolitano, A.J. Marszal, S. Pless, P. Torcellini, K. Voss, Criteria for definition of net zero energy buildings, in: EuroSun Conference Graz, Austria, 2010.

[6] K. Voss, I. Sartori, Nearly-zero, net zero and plus energy buildings - how definitions \& regulations affect the solutions, REHVA European HVAC Journal 6(2012) 85-89, Mathing and Grid Interaction of Net Zero Energy Buildings. EuroSun Conference, Graz, Austria (2010).

[7] International Energy Agency (IEA), Oil Crises and Climate Challenges: 30 Years of Energy Use in IEA Countries, 2004, Paris.

[8] C. Warner, S. Farrar-Nagy, M. Wassmer, B, Stafford, R. King, S. Vega, E. Rodriguez-Ubinas, J. Cronemberger, J. Serra, The 2009 Department of Energy Solar Decathlon and the 2010 European Solar Decathlon: expanding the global reach of zero energy homes through collegiate competitions, in: 34th IEEE Photovoltaic Specialists Conference, Philadelphia, USA, 2009.

[9] K. Voss, I. Sartori, A. Napolitano, S. Geier, H. Gonzalves, M. Hall, P. Heiselberg, J. Widén, J.A. Candanedo, E. Musall, B. Karlsson, P. Torcellin, Load matching and grid interaction of net zero energy buildings, in: EuroSun Conference, Graz, Austria, 2010

[10] K. Voss, E. Musall, M. Lichtmeß, From low energy to net zero energy buildings status and perspectives, Journal of Green Building 6/1 (2011) 46-57.

[11] I. Navarro, A. Gutierrez, C. Montero, E. Rodriguez-Ubinas, E. Matallanas, M. Castillo-Cagigal, M. Porteros, J. Solorzano, E. Caamaño-Martin, M.A. Egido, J.M. Paez, S, Vega, Solar Decathlon Europe 2012: A multidisciplinar educational competition, Tech. Rep, Robolabo, ETSI, Telecomunicacion, Universidad Politecnica de Madrid, Madrid, Spain, 2013.

[12] Solar Decathlon Europe Organization, Solar Decathlon Europe 2010: Rules and Regulations, Madrid, 2010.

[13] Solar Decathlon Europe Organization, Rules of the Solar Decathlon Europe 2012, Madrid, 2012.

[14] A. Gutierrez, M. Castillo-Cagigal, E. Matallanas, I. Navarro, Monitoring of a solar smart house village, Tech. Rep., TR/ROBOLABO/2013-003, Robolabo, ETSI, Telecomunicacion, Universidad Politecnica de Madrid, Madrid, Spain, 2013.
[15] K. Voss, S, Herkel, J. Pfafferott, G. Lohnert, A. Wagner, Energy efficient office buildings with passive cooling - results and experiences from a research and demonstration programme, Solar Energy 81 (3) (2007).

[16] G. Todesco, Super-efficient buildings: how low can you go? ASHRAE Journal 38 (12) (1996) 35-40.

[17] G. Koc, I. Oral, Z. Yilmaz, Building form for cold climatic zones related to building envelope from heating energy conservation point of view, Energy and Buildings 35 (2003) $383-388$.

[18] U.T. Aksoya, M. Inalli, Impacts of some building passive design parameters on heating demand for a cold region, Building and Environment 41 (2006) $1742-1754$.

[19] U. Eicker, Cooling strategies, summer comfort and energy performance of a rehabilitated passive standard office building, Applied Energy 87 (2010) 2031-2039.

[20] D. Chiras, The Solar House: Passive Heating and Cooling, Chelsea Green Publishing, Vermont, 2002

[21] CEN EN 15217, Energy Performance of Buildings - Methods for Expressing Fnergy Performance and for Energy Certification of Buildings, European Committee for Standardization, Brussels, 2007.

[22] B. Su, Building passive design and housing energy efficiency, Architectural Science Review 51 (3) (2008) 277-286.

[23] B. Su, The impact of passive design factors on house energy efficiency, Architectural Science Review 54 (4) (2011) 270-276.

[24] H.E. Mechri, A. Capozzoli, V. Corrado, Use of the ANOVA approach for sensitive building energy design, Applied Energy 87 (2010) 3073-3083.

[25] A. Gasparella, G. Pernigotto, F. Cappelletti, P. Romagnoni, P. Baggio, Analy sis and modelling of window and glazing systems energy performance for a well insulated residential building, Energy and Buildings 43 (4) (2011) 1030-1037.

[26] I. Susorova, M. Tabibzadeh, A. Rahman, H.L. Clack, M. Elnimeiri, The effect of geometry factors on fenestration energy performance and energy savings in office buildings, Energy and Buildings 57 (2013) 6-13.

[27] R. Ourghi, A. Al-Anzi, M. Krarti, A simplified analysis method to predict the impact of shape on annual energy use for office buildings, Energy Conversion and Management 48 (1) (2007) 300-305.

[28] D. Tuhus-Dubrow, M. Krarti, Genetic-algorithm based approach to optimize building envelope design for residential buildings, Building and Environment 45 (7) (2010) 1574-1581.

[29] J. Parasonis, A. Keizikas, A. Endriukaityte, D, Kalibatiene, Architectural solutions to increase the energy efficiency of buildings, Journal of Civil Engineering and Management 18(1)(2012) 71-80.

[30] R. Evins, A review of computational optimisation methods applied to sustainable building design, Renewable and Sustainable Energy Reviews 22 (2013) 230-245.

[31] A. Brownlee, J. Wright, Solution analysis in multi-objective optimization, in: Proc. Building Simulation and Optimisation (BSO12), IBPSA-England, Loughborough University, UK, 2012.

[32] S. Attia, M. Hamdy, W. O'Brien, S. Carlucci, Assessing gaps and needs for integrating building performance optimization tools in net zero energy buildings design, Energy and Buildings 60 (2013) 110-124.

[33] R. Pacheco, J. Ordónez, G. Martínez, Energy efficient design of building: a review Renewable and Sustainable Energy Reviews 16 (2012) 3559-3573.

[34] H.Y. Chan, S.B. Riffat, ]. Zhu, Review of passive solar heating and cooling technologies, Renewable and Sustainable Energy Reviews 14 (2010) 781-789.

[35] Y. Hamada, M. Nakamura, K. Ochifuji, S. Yokoyama, K. Nagano, Development of a database of low energy homes around the world and analyses of their trends, Renewable Energy 28 (2003) 321-328.

[36] E. Rodriguez-Ubinas, B. Arranz Arranz, S. Vega Sánchez, F.]. González, Influence of the use of PCM drywall and the fenestration in building retrofitting, Energy and Buildings 65 (2013) 464-476.

[37] M. Milne, R. Liggett, A. Benson, Y. Bhattacharya, Additions to a Design Tool for Visualizing the Energy Implications of California's Climates. Development and Technology, University of California Energy Institute, Berkeley, 2009.

[38] J.M. Sancho, J. Riesco, C. Jimenez, M.C. Sanchez, J. Montero, M. López, Atlas de Radiación Solar en España utilizando datos del SAF de Clima de EUMETSAT, Agencia Estatal de Meteorología Ministerio de Agricultura, Alimentación y Medio Ambiente, Madrid, 2012

[39] Ministerio de vivienda-Gobierno de España: Código Técnico de la Edificación: Parte 1, 2007. http://www.codigotecnico.org

[40] ASHRAE, Handbook of Fundamentals, American Society of Heating Refrigeration and Air Conditioning Engineers, Inc., Atlanta, 2005

[41] E. Rodriguez-Ubinas, L. Ruiz-Valero, S. Vega, J. Neila, Applications of Phase Change Material in highly energy-efficient houses, Energy and Buildings 50 (2012) 49-62.

[42] S. Vega Sanchez (Ed.), Solar Decathlon Europe 2010: Towards Energy Effi cient Buildings. 10ACTION Project, Intelligent Energy Europe Program, Madrid, 2011.

[43] ASHRAE, Standard 55: Thermal Environmental Conditions for Human Occupancy, American Society of Heating Refrigeration and Air Conditioning Engineers, Inc., Atlanta, 2004

[44] IDAE, Análisis del Consumo energético del sector residencial en España: Informe Final. Proyecto SECH-SPAHOUSEC, Instituto para la Diversificación y el Ahorro de la Energía, Madrid, 2011 